Research Article

\title{
Pattern of anti-diabetic drugs prescribed in a tertiary care hospital of Bangladesh
}

\author{
Zuhayer Ahmed ${ }^{1 *}$, M. A. Hafez ${ }^{2}$, M. A. Bari ${ }^{3}$, Jesmin Akhter $^{3}$
}

${ }^{1}$ Global Alliance for Vaccines \& Immunization (Gavi), Faridpur, Bangladesh

${ }^{2}$ Department of Biostatistics, Bangladesh University of Health Sciences, Dhaka, Bangladesh ${ }^{3}$ Department Public Health, ASA University Bangladesh, Dhaka, Bangladesh

Received: 22 December 2015

Revised: 06 January 2016

Accepted: 08 January 2016

*Correspondence to:

Dr. Zuhayer Ahmed,

Email: zuhayerbabu@gmail.com

Copyright: (C) the author(s), publisher and licensee Medip Academy. This is an openaccess article distributed under the terms of the Creative Commons Attribution NonCommercial License, which permits unrestricted noncommercial use, distribution, and reproduction in any medium, provided the original work is properly cited.

\begin{abstract}
Background: Globally, diabetes mellitus is a common endocrine disorder. This study was conducted for collecting the demographic details of diabetic patients and determining the pattern of drugs prescribed among them in outpatient department of a tertiary healthcare center.

Methods: A descriptive type of cross-sectional study was carried out at the outpatient department of Endocrinology, Dhaka Medical College Hospital, Bangladesh from 1 May to 31 July, 2015. Diabetic patients receiving the management for at least 6 months were enrolled and interviewed by the researchers after getting informed written consent. Structured case record form was used for demographic data \& prescription details. Data were analysed using computer in SPSS 22 and Microsoft Excel 2010.
\end{abstract}

Results: Altogether 105 patients, 40 males $(38.1 \%)$ and 65 females $(61.9 \%)$ were enrolled with urban predominance $(69.5 \%)$ where $51(48.6 \%)$ were in the age group 47-61 years with a mean of $53.4(\mathrm{SD} \pm 10.6)$ years. $70(66.7 \%)$ had diabetic history of less than 5 years and $66(62.9 \%)$ had at least one concurrent illness. Hypertension accounted for majority (34.3\%) of complications. On an average, $5.62(\mathrm{SD} \pm 3.16)$ drugs were advised per prescription for diabetes as well as associated co-morbidities and majority (23.8\%) had 4 drugs. The majority of drugs $(74.3 \%)$ were from local manufacturers. Most patients $(62.9 \%)$ were prescribed with oral drugs singly. Metformin alone predominated in $41 \%$ prescriptions followed by the combination of Metformin and Sitagliptin (31.4\%).

Conclusions: The findings can serve as a guide to choose the formulation and combination of anti-diabetic drugs in this part of the world before developing \& marketing any new drug.

Keywords: Drug utilization, Hypoglycemic agents, Tertiary healthcare

\section{INTRODUCTION}

Diabetes Mellitus (DM) is a common and very prevalent disease affecting about $25 \%$ of world population of both developed and developing countries. ${ }^{1,2}$ The number of people developing DM is currently increasing worldwide in an alarming exponential proportions; this may be connected to a rapid rise in risky health behaviors, urbanization and aging. There is an estimate of over 200 million people with diabetes in the world, $80 \%$ of whom reside in developing countries and is expected to be the most prevalent non-communicable disease by 2025 . $^{2,3} \mathrm{~A}$ recent meta-analysis showed that the prevalence of diabetes among adults had increased substantially, from
$4 \%$ in $1995-2000$ and $5 \%$ in $2001-2005$ to $9 \%$ in 20062010 periods in Bangladesh. ${ }^{4}$ This country had a population of 149.8 million in $2011 .^{5}$ According to the International Diabetes Federation, the prevalence will be $13 \%$ by $2030 .^{6}$ There is paucity of data regarding drug use pattern in diabetic patients in Bangladesh. Study related to drug utilization of anti-diabetic drugs is of paramount importance to promote rational drug use and disseminate valuable information to health teams to ensure that. We can also say that irrational prescribing can lead to increased cost of drugs, which often leads to non-adherence. ${ }^{7}$ 
A study from the United States of America (USA) reported that about 1.3 million adults with disabilities did not take their medications as prescribed because of cost and as a result, more than half reported health problems later. $^{8}$ For better control of DM with minimal complications of drugs, this information has no alternatives. A study on drug utilization can provide valuable information to the physicians, researchers, policy makers and the drug \& therapeutics committee members to determine the drug use pattern. ${ }^{7}$

This study is, therefore, aimed at determining the pattern of prescription among diabetic patients relevant to current evidence and clinical guidelines. We tried to describe the socio-demographic characteristics of the diabetic patients getting prescription in Dhaka Medical College Hospital of Bangladesh and identify the pattern of prescriptions of hypoglycemic agents among them.

\section{METHODS}

\section{Study design and population}

It is a descriptive type of cross-sectional study conducted for a period of 3 months from 1 May to 31 July, 2015 among the diabetic patients, irrespective of age, sex and race, attending the outpatient department of diabetic clinic of Dhaka Medical College Hospital (DMCH) in Dhaka.

\section{Eligibility criteria \& sampling technique}

All diabetic patients who were willing to attend the study and were in optimal mental condition and receiving management for at least 6 months, irrespective of age, sex and race, attending the outdoor facility of diabetic clinic of DMCH. The patients who were disoriented or declining to participate in the study were excluded. Patients meeting the inclusion criteria \& devoid of exclusion criteria were approached following purposive type of non-probability sampling technique, while they were waiting to see the physician. An interview was taken with a semi-structured case record form after getting informed written consent of the respondents. Demographic data as well as data on prescription were collected with this case record form.

\section{Sample size}

At $5 \%$ margin of error and $95 \%$ confidence level, target sample size was determined using the following simple formula: ${ }^{9}$

$$
n=\frac{Z^{2} P(1-P)}{m^{2}}
$$

Where,

$\mathrm{n}=$ Sample size

$\mathrm{Z}=\mathrm{Z}$ statistic for a level of confidence (At $95 \%$

Confidence level, $Z=1.96$ )
$\mathrm{P}=$ Expected prevalence or proportion

$\mathrm{m}=$ Margin of Error (in proportion of one; if $5 \%, \mathrm{~m}=$ $0.05)$

$$
n=\frac{(1.96)^{2} \times .09 \times .91}{(0.05)^{2}}=126
$$

In this study, due to time constraints, the researchers collected 105 samples.

Statistical methods Data were analysed, particularly mean, standard deviation and percentages were calculated and chi-square tests were done using SPSS v.22 while figures and tables were prepared using Microsoft Excel 2010. Categorical variables were presented in percentages.

\section{RESULTS}

Table 1: Distribution of respondents by sex.

\begin{tabular}{|lll|}
\hline Sex & Number of respondents & Percentage \\
\hline Male & 40 & 38.1 \\
\hline Female & 65 & 61.9 \\
\hline Total & 105 & 100 \\
\hline
\end{tabular}

Table 2: Distribution of the level of education of respondents.

\begin{tabular}{|lll|}
\hline Level of education & Number & Percentage \\
\hline Below primary & 10 & 9.5 \\
\hline Primary & 41 & 39.0 \\
\hline Secondary & 20 & 19.0 \\
\hline Higher secondary & 19 & 18.1 \\
\hline Graduate & 8 & 7.6 \\
\hline Post graduate & 7 & 6.7 \\
\hline Total & 105 & 100 \\
\hline
\end{tabular}

Table 3: Distribution of religious status of the respondents.

\begin{tabular}{|ll|l|}
\hline Religion & Number & Percentage \\
\hline Islam & 85 & 81.0 \\
\hline Hinduism & 18 & 17.1 \\
\hline Christianity & 1 & 1.0 \\
\hline Buddhism & 1 & 1.0 \\
\hline Total & 105 & 100 \\
\hline
\end{tabular}

Among the total 105 respondents with mean age of 53.42 $(\mathrm{SD} \pm 10.587)$ years, $40(38.1 \%)$ were male and 65 $(61.9 \%)$ female (Table 1) with male: female ratio of $0.62: 1$. Majority $(69.5 \%)$ were from urban area and among them about $27.6 \%$ were male and $41.9 \%$ were female. The study revealed high prevalence $(48.6 \%)$ of diabetes in 47-61 year age group (Figure 1). 39\% were from primary level and only $6.7 \%$ were from post graduate group (Table 2). Majority $(65.7 \%)$ were from monthly income of Tk. 4001-28000 group (Figure 2) with mean income of Tk. 26882.81 (SD \pm 14391.938). 
$81 \%$ of the respondents were Muslim and $17.1 \%$ Hindu (Table 3). 51.4\% patients were diagnosed for less than 5 years while $17.1 \%$ were diagnosed beyond 10 years (Table 4). Majority (62.9\%) of the patients were prescribed oral drugs singly and $8.6 \%$ injectable preparations alone (Figure 3). Among injectable drugs, majority (48.7\%) had prescription of short acting insulin alone and $35.9 \%$ with mixed insulin preparation (Table 5). 66 patients had at least one co-morbidity and hypertension predominated $(21.9 \%)$ the list (Table 6).

Table 4: Distribution of duration of diabetes mellitus.

\begin{tabular}{|c|c|c|c|c|c|c|}
\hline \multirow{3}{*}{$\begin{array}{l}\text { Duration of diabetes } \\
\text { mellitus }\end{array}$} & \multicolumn{4}{|l|}{ Sex } & \multirow{3}{*}{ Number } & \multirow{3}{*}{$\%$} \\
\hline & \multicolumn{2}{|l|}{ Male } & \multicolumn{2}{|l|}{ Female } & & \\
\hline & Number & $\%$ & Number & $\%$ & & \\
\hline$<5$ years & 22 & 21.0 & 32 & 30.5 & 54 & 51.4 \\
\hline 5-10 years & 13 & 12.4 & 20 & 19.0 & 33 & 31.4 \\
\hline$>10$ years & 5 & 4.8 & 13 & 12.4 & 18 & 17.1 \\
\hline Total & 40 & 38.1 & 65 & 61.9 & 105 & 100 \\
\hline
\end{tabular}

Table 5: Distribution of the injectable anti-diabetic drugs prescribed $(n=39)$.

\begin{tabular}{|lll|}
\hline Injectable drugs & Frequency & Percentage \\
\hline Short acting insulin & 19 & 48.7 \\
\hline Intermediate acting insulin & 1 & 2.6 \\
\hline Mixed insulin & 14 & 35.9 \\
\hline $\begin{array}{l}\text { Short acting + Intermediate } \\
\text { acting insulin }\end{array}$ & 5 & 12.8 \\
\hline Total & 39 & 100 \\
\hline
\end{tabular}

On an average, $5.62(\mathrm{SD} \pm 3.163)$ drugs were prescribed per prescription where majority $(54.2 \%)$ had 4-6 drugs (Table 7). $41 \%$ were prescribed Metformin alone and 31.4\% Combination of Metformin and Sitagliptin (Figure 4). Majority (74.3\%) of the drugs were from local manufacturers (Table 8).

\section{DISCUSSION}

Out of 105 patients evaluated in the study, 40 (38.1\%) were males and $65(61.9 \%)$ were females. Females predominated in the study population which is in agreement with the result of a study in Taiwan, which indicated a possible epidemiological transition. ${ }^{10}$ This result does not corroborate with the findings of a cohort study conducted in the U.S. which also reported a male preponderance for DM. ${ }^{11}$

Majority (69.5\%) of the respondents were from urban area, which corresponds to a previous study in Bangladesh. $^{12}$ Similar findings have been reported previously in Bangladesh in another study (8\% versus $4 \%$ in the two groups, respectively). ${ }^{13}$ Urban people have a more sedentary lifestyle or different dietary habits and are more likely to be overweight or obese, which may be the cause of DM to be more prevalent among them. ${ }^{14}$
Table 6: Distribution of co-morbidities associated with diabetes mellitus

\begin{tabular}{|lll|}
\hline Name of Co-morbidity & Frequency & Percentage \\
\hline BEP & 2 & 1.9 \\
\hline Cataract & 2 & 1.9 \\
\hline Cataract, and Hypertension & 2 & 1.9 \\
\hline $\begin{array}{l}\text { Cataract, Hypertension and } \\
\text { CKD }\end{array}$ & 1 & 1.0 \\
\hline CKD & 4 & 3.8 \\
\hline CKD with Hypertension & 2 & 1.9 \\
\hline COPD & 1 & 1.0 \\
\hline Hypertension & 23 & 21.9 \\
\hline Hypertension, IHD & 1 & 1.0 \\
\hline Hypertension, Obesity & 1 & 1.0 \\
\hline Hypertension with PD & 1 & 1.0 \\
\hline Hypertension with Stroke & 2 & 1.9 \\
\hline $\begin{array}{l}\text { Hypertension with Stroke } \\
\text { and CKD }\end{array}$ & 2 & 1.9 \\
\hline $\begin{array}{l}\text { Hypertension with Stroke and } \\
\text { PD }\end{array}$ & 1 & 1.0 \\
\hline Hypothyroidism & 2 & 1.9 \\
\hline IBS & 1 & 1.0 \\
\hline IHD & 2 & 1.9 \\
\hline LBP & 1 & 1.0 \\
\hline Stroke with CKD & 2 & 1.9 \\
\hline Osteoarthritis & 6 & 5.7 \\
\hline Stroke & 7 & 6.7 \\
\hline None & 39 & 37.1 \\
\hline Total & 105 & 100.0 \\
\hline BEP Benign entargement of protat & CKD: Chonich \\
\hline
\end{tabular}

BEP: Benign enlargement of prostate; CKD: Chronic kidney disease; COPD: Chronic obstructive pulmonary disease, IHD: Ischemic heart disease; PD: Parkinson's disease; IBS: Irritable bowel syndrome; LBP: Low back pain. 
The (Mean \pm SD) age of the patients was 53.42 $(\mathrm{SD} \pm 10.587)$ years with a range between 20 and 76 years. It was higher than that reported in studies carried out in India $(51.5 \pm 12.3$ years $)$, lower to that reported in Hong Kong ( $56.5 \pm 12.6$ years). ${ }^{15,16}$

Maximum patients with DM were from the age group of 47 to 61 years followed by the age group of more than 62 and 31 to 46 , which corresponds to a study in India. ${ }^{17}$
Greater prevalence in this age group may be due to change in life style, lack of physical exercise and stress. ${ }^{17}$ A total 66 patients suffered from comorbid conditions. Hypertension accounted for $34.3 \%$ of the total complications which was lower than in the study reported in Nepal. ${ }^{7}$ Our study findings are also similar to the study conducted by Arauz-Pacheco et al; in Texas medical center that hypertension is more common complication affecting $20-60 \%$ of people with diabetes. ${ }^{18}$

Table 7: Distribution of the number of drugs prescribed for DM and associated co-morbidities according to sex.

\begin{tabular}{|c|c|c|c|c|c|c|}
\hline \multirow{3}{*}{$\begin{array}{l}\text { Total number of drugs } \\
\text { prescribed for everyday }\end{array}$} & \multicolumn{4}{|l|}{ Sex } & \multirow{3}{*}{ Frequency } & \multirow{3}{*}{$\%$} \\
\hline & \multicolumn{2}{|l|}{ Male } & \multicolumn{2}{|l|}{ Female } & & \\
\hline & Number & $\%$ & Number & $\%$ & & \\
\hline $1-3$ & 10 & 9.5 & 13 & 12.4 & 23 & 21.9 \\
\hline $4-6$ & 20 & 19.0 & 37 & 35.2 & 57 & 54.2 \\
\hline $7-9$ & 5 & 4.8 & 10 & 9.5 & 15 & 14.3 \\
\hline $10-12$ & 2 & 1.9 & 2 & 1.9 & 4 & 3.8 \\
\hline $13-15$ & 1 & 1.0 & 2 & 1.9 & 3 & 2.9 \\
\hline $16-18$ & 2 & 1.9 & 1 & 1.0 & 3 & 2.9 \\
\hline Total & 40 & 38.1 & 65 & 61.9 & 105 & 100 \\
\hline
\end{tabular}

Table 8: Distribution of dosage formulation according to the manufacturers of the anti-diabetic drugs.

\begin{tabular}{|c|c|c|c|c|c|c|c|c|}
\hline \multirow{3}{*}{$\begin{array}{l}\text { Manufacturer of } \\
\text { the anti-diabetic } \\
\text { drugs }\end{array}$} & \multicolumn{6}{|c|}{ Dosage formulation of anti-diabetic agents prescribed } & \multirow{3}{*}{ Frequency } & \multirow{3}{*}{$\%$} \\
\hline & \multicolumn{2}{|c|}{ Oral } & \multicolumn{2}{|c|}{ Parenteral } & \multicolumn{2}{|l|}{ Both } & & \\
\hline & Number & $\%$ & Number & $\%$ & Number & $\%$ & & \\
\hline Local & 66 & 62.9 & 3 & 2.9 & 9 & 8.6 & 78 & 74.3 \\
\hline Multinational & 0 & 0 & 2 & 1.9 & 0 & 0 & 2 & 1.9 \\
\hline Both & 0 & 0 & 4 & 3.8 & 21 & 20.0 & 25 & 23.8 \\
\hline Total & 66 & 62.9 & 9 & 8.6 & 30 & 28.6 & 105 & 100 \\
\hline
\end{tabular}

$\mathrm{X}^{2}=143.377 ; \mathrm{df}=4, \mathrm{p}=0.000$

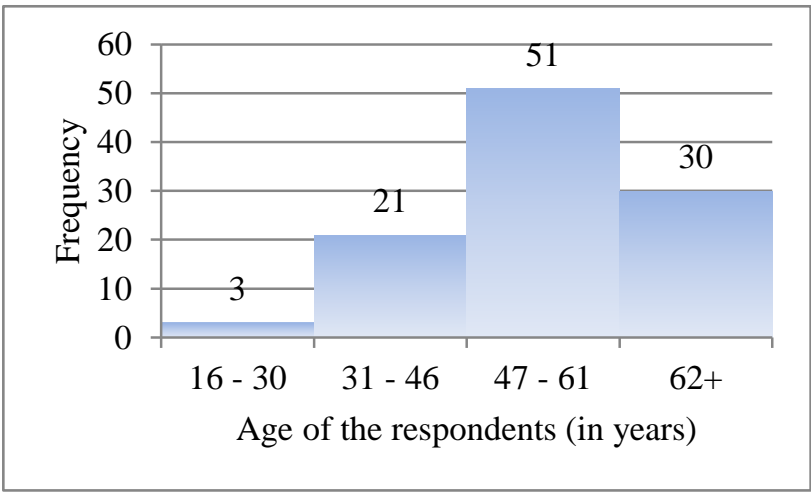

Figure 1: Distribution of age group of the respondents.

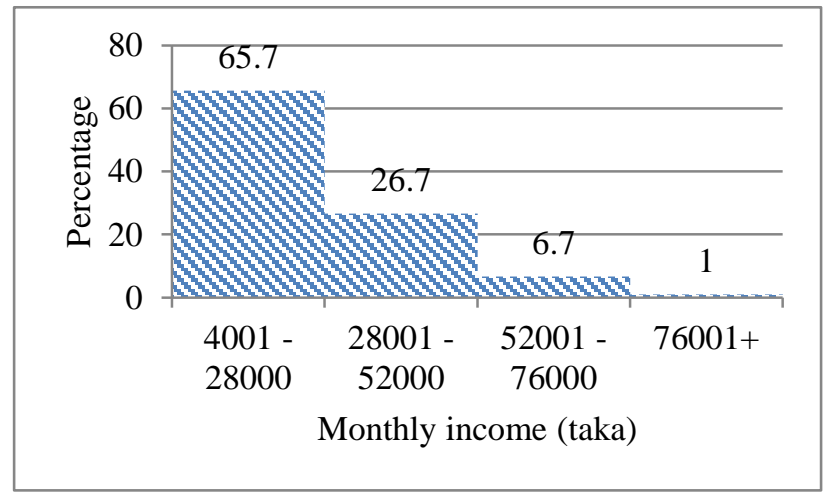

Figure 2: Distribution of monthly family income. 


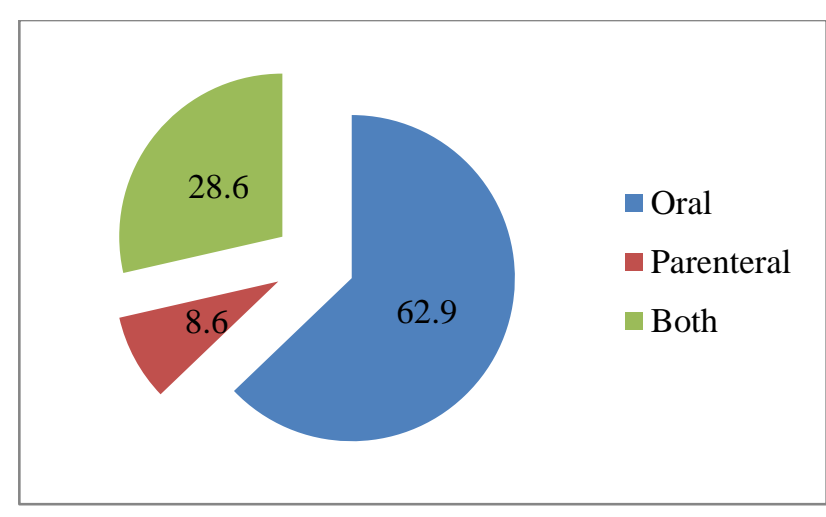

Figure 3: Distribution of dosage formulations.

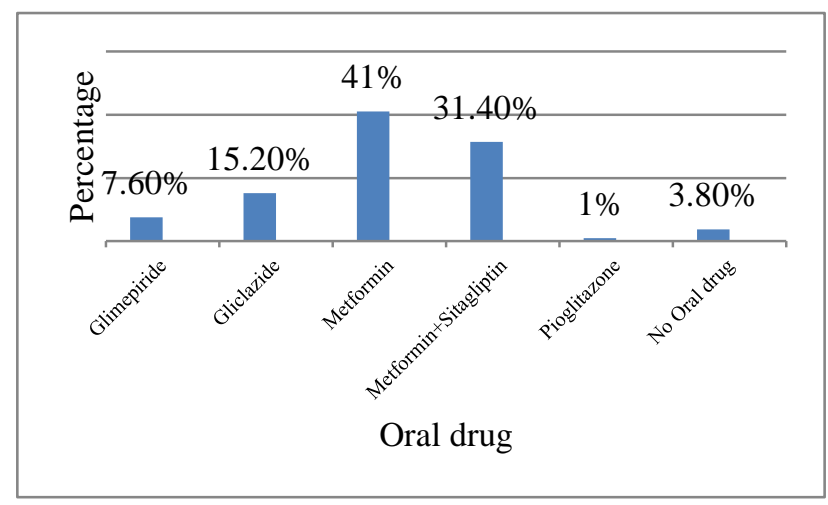

Figure 4: Distribution of prescribed oral anti-diabetic drugs.

Figure 1 showing the distribution of age group of the respondents. Respondents' age was divided into four groups. Majority of them (48.6\%) were from 47-61 year age group. Their mean age was 53.42 ( $\mathrm{SD} \pm 10.587)$ years.

Figure 2 showing the distribution of monthly family income of the patients. Majority $(65.7 \%)$ were from Tk. 4001-28000 group. About 26.7\% were from Tk. 2800152000 group. Respondent's mean income was Tk. 26882.81 ( $\mathrm{SD} \pm$ 14391.938).

Figure 3 showing the distribution of dosage formulations. 30 were prescribed with both the oral and injectable drugs concurrently among 105 respondents. Majority $(62.9 \%)$ were prescribed oral drugs singly and $8.6 \%$ injectable preparations alone.

Figure 4 showing the distribution of the prescribed oral anti-diabetic drugs. It was found that among 105 respondents, $43(41 \%)$ were prescribed Metformin alone and $31.4 \%$ Combination of Metformin and Sitagliptin. $3.8 \%$ patients were not prescribed any oral drug.
It was found that among 105 respondents, 43 (41\%) were prescribed Metformin alone, which was the most and corraborates with other studies. ${ }^{17,19}$ Metformin and Sitagliptin was the most common drug in combination (31.4\%). Majority (62.9\%) was prescribed oral drugs singly, most probably due to the ease of administration. ${ }^{17}$ Only $39(37.1 \%)$ were prescribed injectable hypoglycemic agents. Among them, majority (48.7\%) were prescribed short acting insulin alone and $35.9 \%$ with mixed insulin preparation.

The duration of Diabetes Mellitus shows that, majority $(51.4 \%)$ was diagnosed for within last 5 years. $17.1 \%$ were diagnosed beyond 10 years, indicating that patients present to the physicians more immediately after diagnosis.

About the dosage formulation of prescribed anti-diabetic agents, 30 were prescribed both oral and injectable drugs concurrently among 105 respondents. Majority (62.9\%) were prescribed oral drugs singly and $8.6 \%$ injectable preparations alone.

Among the 105 respondents, the majority (54.2\%) was prescribed 4-6 drugs and only $1.9 \%$ had maximum number of 17 drugs. The average number of drugs prescribed was $5.62(\mathrm{SD} \pm 3.163)$ per prescription. In general, due to multiple co-morbidities, diabetic patients are at a greater risk of polypharmacy. Previous studies from a tertiary care hospital in Nepal identified lacunae in drug use pattern in the hospital. ${ }^{20,21}$

Local manufacturers had their majority $(74.3 \%)$ of drugs in the prescription. Anti-diabetic drugs produced by both local and multinational manufacturers were in $23.8 \%$ prescriptions.

\section{CONCLUSION}

Oral anti-diabetic drugs were advised in majority, which is easier method of drug administration. Physician's preference was influenced or modified in some circumstances. However, this study found an underutilization of sulphonylureas and metforminsulphonylurea combination, indicating the need for continuing medical education for physicians to more rationalize while choosing hypoglycemic agents. There is always a huge scope for improving prescription writing and treatment adherence by generic name. To reduce morbidity and mortality in diabetic patients, we must ensure optimum glycemic control not only by prescribing keeping in line with guidelines, but also by ensuring patients' adherence to treatment plan. 


\section{Limitations of the study}

A larger study with probability sampling could not be possible due to time constraints \& monsoon season. Certain information was recorded according to the statement of the respondents; as such the validity of the results was dependent on the validity of the statement given by the respondent, though data were recorded after careful judgment and calculation by the researchers.

\section{Recommendations}

Depending upon the study findings, we can say that for better understanding of the pattern of prescription of hypoglycemic agents, larger study with probability sampling should be conducted. Health education should be given great importance in the mass media for diabetic patients irrespective of age, sex and area of residence, as it is one of the most effective tools for promotion of health. This will increase the adherence level for the patients. For the same purpose, awareness programs about diabetes control can be organized regularly.

\section{Funding: No funding sources}

Conflict of interest: None declared

Ethical approval: The study was approved by the Institutional Ethics Committee

\section{REFERENCES}

1. Afolayan A, Sunmonu T. In vivo Studies on Antidiabetic Plants Used in South African Herbal Medicine. Journal of clinical biochemistry and nutrition. 2010;47(2):98-106.

2. Khandelwal N. Prevention and management of Diabetes Mellitus in Ayurveda. Asian journal of Biomedical and Pharmaceutical Sciences. 2012;2(6). doi:10.15272/ajbps.v2i6.30.

3. Zargar H, Wani I, Masoodi SR, Laway B, Bashir MI. Mortality in diabetes mellitus--data from a developing region of the world. Diabetes research and clinical practice. 1999;43(1):67-74.

4. Saquib N, Saquib J, Ahmed T, Khanam MA, Cullen MR. Cardiovascular diseases and type 2 diabetes in Bangladesh: a systematic review and meta-analysis of studies between 1995 and 2010. BMC Public Health. 2012;12:434.

5. Bangladesh Population and Housing Census 2011. Dhaka; Bangladesh Bureau of Statistics, Government of the People's Republic of Bangladesh; 2012.

6. Whiting DR, Guariguata L, Weil C, Shaw J. IDF Diabetes Atlas: Global estimates of the prevalence of diabetes for 2011 and 2030. Diabetes Research and Clinical Practice. 2011;94(3):311-21.

7. Dinesh KU, Subish P, Pranaya M. Pattern of potential drug-drug interactions in diabetic outpatients in a Tertiary Care Teaching Hospital in
Nepal. Medical Journal of Malaysia. 2007;62(4):2948.

8. Kennedy J, Erb C. Prescription noncompliance due to cost among adults with disabilities in the United States. American journal of public health. 2002;92(7):1120-4.

9. Daniel W. Biostatistics: A Foundation for Analysis in the Health Sciences (10th Edition). New York: John Wiley \& Sons. 1999;30(7).

10. Tseng $\mathrm{CH}$. The Epidemiologic Transition of Diabetes Mellitus in Taiwan: Implications for Reversal of Female Preponderance from a National Cohort. The Open Diabetes Journal. 2009;2:18-23.

11. Boccuzzi SJ, Wogen J, Fox J, Sung JCY, Shah AB, Kim J. Utilization of Oral Hypoglycemic Agents in a Drug-Insured U.S. Population. Diabetes Care. 2001;24(8):1411-5.

12. Akter S, Rahman MM, Abe SK, Sultana P. Prevalence of diabetes and prediabetes and their risk factors among Bangladeshi adults: a nationwide survey. Bulletin of the World Health Organization. 2014;92(3):204-13.

13. Abu Sayeed M, Hussain MZ, Rumi MA, Banu A, Azad Khan AK. Effect of socioeconomic risk factors on the difference in prevalence of diabetes between rural and urban populations in Bangladesh. Diabetes Care. 1997;20(4):551-5.

14. Shafique S Stallkamp G, de Pee S, Panagides D, Bloem MW. Trends of under- and overweight among rural and urban poor women indicate the double burden of malnutrition in Bangladesh. Int $\mathbf{J}$ Epidemiol. 2007;36:449-57.

15. Sultana G, Kapur P, Aqil M, Alam MS, Pillai KK. Drug utilization of oral hypoglycemic agents in a university teaching hospital in India. Journal of clinical pharmacy and therapeutics. 2010;35(3):26777.

16. Wu SY, Lung BC, Chang S, Lee SC, Critchley J, Chan JC. Evaluation of drug usage and expenditure in a hospital diabetes clinic. Journal of clinical pharmacy and therapeutics. 1998;23(1):49-56.

17. Vengurlekar S, Patidar P, Bafna R, Jain S. Prescribing pattern of antidiabetic drugs in indore city hospital. Indian J Pharm Sci. 2008;70(5):637-40.

18. Arauz-Pacheco C, Parrott MA, Raskin ArauzPacheco C, Parrott MA. The treatment of hypertension in adult patients with diabetes. Diabetes Care. 2002;25(1):134-47.

19. Patel B, Oza B, Patel K, Malhotra S, Patel V. Pattern of antidiabetic drugs use in type-2 diabetic patients in a medicine outpatient clinic of a tertiary care teaching hospital. International Journal of Basic \& Clinical Pharmacology. 2013;2(4):485.

20. Shankar RP, Partha P, Shenoy NK, Easow JM, Brahmadathan KN. Prescribing patterns of antibiotics and sensitivity patterns of common microorganisms in the Internal Medicine ward of a 
teaching hospital in Western Nepal: a prospective study. Annals of clinical microbiology and antimicrobials. 2003;2:7.

21. Alam K, Mishra P, Prabhu M, et al. A study on rational drug prescribing and dispensing in outpatients in a tertiary care teaching hospital of
Western Nepal. Kathmandu Univ Med J. 2006;4(4):436-43.

Cite this article as: Ahmed Z, Hafez MA, Bari MA, Akhter J. Pattern of anti-diabetic drugs prescribed in a tertiary care hospital of Bangladesh. Int J Basic Clin Pharmacol 2016;5:6-12. 